\title{
Vitamin D Status, C-Reactive Protein and Risk of Coronary Artery Disease- A Hospital-Based Study
}

\author{
Adham I. Ahmed \\ Faculty of Intermediate Studies, University of Palestine, Gaza, Palestine \\ Email: Rn.adham@gmail.com \\ Received 6 October 2014; revised 25 November 2014; accepted 17 December 2014 \\ Copyright (C) 2014 by author and Scientific Research Publishing Inc. \\ This work is licensed under the Creative Commons Attribution International License (CC BY). \\ http://creativecommons.org/licenses/by/4.0/

(c) (i) Open Access

\begin{abstract}
Coronary artery disease (CAD) is a leading cause of deaths of women and men worldwide. In this study we tried to assess the relationship between Vitamin D status and CAD. Vitamin D has a big role in the body and debate on its effect on the heart and coronary arteries still exits. C-reactive protein (CRP) is an inflammatory marker which may rise in CHD. Aim: To determine the relationship between Vitamin $D$ status and CRP and CAD risk among patients at middle zone of the Gaza Strip. Methodology: A retrospective case-control, hospital-based study was conducted at Al-Aqsa Martyr's Hospital in Dier El-Balah City from August 2014 to October 2014. Patients $(n=100)$ aged above 40 years with confirmed CAD history were recruited using a purposeful, non-random sampling. Vitamin D status assessed by food frequency questionnaire of dietary Vitamin D and serum Vitamin D. Serum Vitamin D was measured using Calbiotech's 25-0H Vitamin D ELISA and serum CRP was measured by the latex agglutination. SPSS V.19 used for data analysis. Results: Mean of age among cases was $(68.28 \pm 8.01)$ higher than controls $(57.82 \pm 9.61)(P=0.01)$; percent of males (54\%) was higher than females $(46.0 \%)$ among cases. Sun exposure and mean duration of daily exposure to sunlight were higher in cases $(P>0.05)$. Cases were consumed less servings of Vitamin $D$ rich food than controls $(P>0.05)$. Percent of Vitamin $D$ deficiency among cases $(42 \%)$ was higher than controls $(16.0 \%)(P=0.002)$. Mean of serum Vitamin $D$ in association with positive CRP was $(79.95 \pm 70.6)$ lower than those with negative CRP $(106.06 \pm 68.966)(P=0.13)$. Percent of positive serum CRP among cases $30 \%$ was higher than controls $10 \%(P=0.01)$. Conclusion: Vitamin D deficiency was associated with positive CRP in patients with CAD. Vitamin D may have an anti-inflammatory effect regarding to our results.
\end{abstract}

\section{Keywords}

Vitamin D Status, C-Reactive Protein, Coronary Artery Disease, Risk, Palestine 


\section{Introduction}

Coronary artery disease (CAD) is global health problem which associated with multiple causes. In this study we focused on the relationship between CAD and Vitamin D. CAD is a leading cause of death of women and men worldwide [1]. In the United States 600,000 people die of heart disease every year-that's 1 in every 4 deaths [2]. Cardiovascular disease (CVD) was the first leading cause of death (22.4\%) in Palestine in 2011, succeeded by cancer deaths (12.4\%) and cerebrovascular diseases (10.3\%) [3].

Atherosclerosis is the main cause of CAD. Atherosclerosis is a chronic inflammation of the arteries that develops under the action of risk factors. It begins as qualitative changes in endothelial cells; under the action of oxidative, hemodynamic, or biochemical stimuli (such as smoking, hypertension, dyslipidemia) and inflammatory factors, they change their permeability to promote the entry and retention of blood-borne monocytes and low density lipoprotein (LDL) [4] [5]. The atherosclerotic lesion contains cytokines that provoke the production of many inflammatory and cytotoxic molecules in macrophages and vascular cells [6] and also promote the antiatherosclerotic immune reactions [7]. This results in elevation of interleukin-6 and C-reactive protein (CRP) which may be detected in the peripheral circulation [8] [9]. CRP is an inflammatory marker that elevates in patients with CAD caused by inflammation in the coronary artery rather than in the ischemic myocardium [10] [11].

Intervention trials and accumulating evidence from experimental, clinical, and epidemiological studies suggest that Vitamin D may also be associated with several indices of vascular function, including the development and progression of atherosclerotic cardiovascular disease [12]-[14].

Vitamin D receptors are present in vascular smooth muscle, endothelium, and cardiomyocytes and may have an impact on CAD. Observational studies found association between Vitamin D deficiency, high blood pressure, CAD and subsistent CVD [14]. Vitamin D deficiency is associated with increased levels of inflammation and oxidative load; a prospective study included 3000 male and female patients and more scheduled for coronary angiography showed a positive relationship between Vitamin D deficiency and CVD as well as all-cause mortality [15].

Vitamin D comes in two forms: Vitamin D2 (ergocalciferol) and Vitamin D3 (cholecalciferol). Vitamin D2, which exists in plants, is the product of ultraviolet B (UVB) $(290$ to $315 \mathrm{~mm})$ irradiation of ergosterol, and can be consumed as a supplement or in fortified foods. Vitamin D3, a product of UVB irradiation of 7-dehydrocholesterol, is synthesized in the human epidermis or consumed in fish, eggs, cod liver oil, fortified foods and supplements and it can be obtained from the action of sunlight on the skin [16]. New recommendations from the Institute of Medicine (IOM) indicated for necessity of increasing the recommended dietary allowance (RDA) of Vitamin D to be 600 international units (IU) for everyone aged 1 - 70, and raising it to 800 IU for adults older than 70 [17]. The factors affected serum Vitamin D levels are aging, skin pigmentation, sunlight exposure, diet, residence, physical inactivity and obesity; moreover there are some diseases which may affect Vitamin D status such as malabsorption disorders, liver dysfunction and kidney disease [18].

The effect of Vitamin D on cardiovascular health is controversial. Observational studies conclude that Vitamin D supplementation is not convincing in reduction of CVD risk. Meta-analysis conducted by the Endocrine Society Task Force including 51 interventional studies, found no significant effect of Vitamin D on any of the outcome measures, including stroke, myocardial infarction and death [19]. There was also no effect of Vitamin D on secondary outcomes, like lipid profile, serum glucose or blood pressure [20]. Additionally, an original study in postmenopausal women by Truesdell et al. [21] concluded no association between serum Vitamin D and CVD factors assessed by Framingham Cardiovascular Risk Score. Our study aimed at determining the relationship between Vitamin D status and C-CRP and the CAD risk. We hypothesized that this relation might be explained, in part, by the anti-inflammatory properties of Vitamin D and CRP and risk of CHD.

\section{Methodology}

\subsection{Study Design}

The study was a retrospective case control, hospital-based study, conducted at the Al-Aqsa Martyrs' Hospital, middle zone of the Gaza Strip, from August 2014 to October 2014.

\subsection{Study Population and Sampling}

The target population was patients with CAD visited the out-patient clinics of Al-Aqsa Martyrs' Hospital for 
follow up. And other fellows without any suspicion of CHD at other departments who are above 40 years. They were recruited according to the inclusion criteria in the study after getting their consent. A purposeful, nonrandom sample included 100 participants according to the eligibility criteria.

\subsection{Eligibility Criteria}

Inclusion criteria of cases included those diagnosed with CAD who are above 40 years, and in controls included patients without CAD who were above 40 years.

Exclusion criteria for cases and controls involved those with congestive heart failure, gastrointestinal disease, liver or kidney diseases, diabetes mellitus, hyperthyroidism or hyperparathyroidism.

\subsection{End-Point Ascertainment and Definitions}

CAD occurs when a substance called plaque builds up in coronary arteries that lead to arteriosclerosis which is leading-cause of myocardial ischemia and myocardial infarction [22]. Vitamin D status is often defined by serum level of Vitamin D concentrations and there are various terms used to describe Vitamin D status such as sufficiency, insufficiency and deficiency [23].

Serum Vitamin D is the major circulating metabolite of Vitamin D and reflects Vitamin D inputs from cutaneous synthesis and dietary intake. The serum Vitamin D level is the standard clinical measure of Vitamin D status [18] [24]. The serum levels of Vitamin D concentrations are as shown in Table 1 [25].

Serum CRP level was determined using slide agglutination test and reference value was (up to $6 \mathrm{mg} / \mathrm{L}$ ) [26].

\subsection{Assessment of Dietary Vitamin D Intake}

Data on usual diet was ascertained by using the food frequency questionnaire (FFQ). For each food item, each participant was asked how often, on average, he/she had consumed a specified portion size over the past month. We made a list of the richest food of Vitamin D available depending on the United States Agriculture Department (USDA) food database [27]. The $t$ test was used to assess the difference of servings consumed among participants.

\subsection{Measurement of Biochemical Variables}

Serum Vitamin D was measured using Calbiotech's 25-OH Vitamin D ELISA (Spring Valley, CA) in situ Vitamin D ELISA for the quantitation of the total 25(OH) Vitamin D [both 25(OH) Vitamin D2 and D3 forms of Vitamin D [28], and also serum CRP was measured by the latex agglutination machine with a kit from (Inmesco GmbH—Germany) CRP latex slide test (serology kit) is used for the semi-quantitative measurement [29].

\subsection{Assessment of Other Factors}

Lifestyle and dietary data were derived from the questionnaire administered. Personal data; including age, sex, type of dwelling, and sun exposure. Average of servings and daily intake of Vitamin D rich food intake was computed with the use of a semi quantitative food-frequency questionnaire. The questionnaires were validated by a specialists and face validity was used for other measurements.

\subsection{Statistical Analysis}

A univariate analysis was carried out using the Chi-square test for categorical variables and a Student's t-test for continuous variables to compare characteristics of participants between those with and without Vitamin D

Table 1. Serum levels of Vitamin D concentrations.

\begin{tabular}{ccc}
\hline Vitamin D level & $\mathbf{n m o l} / \mathbf{L}$ & $\mathbf{n g} / \mathbf{m L}$ \\
\hline Optimal/sufficient & 75 and more & 30 and more \\
Insufficiency & $51-74$ & $21-29$ \\
Deficiency & 50 and less & 20 and less \\
\hline
\end{tabular}


deficiency. Statistical Package for the Social Sciences (SPSS) program version 19, a P-value of $<0.05$ was considered statistically significant.

\subsection{Ethical Consideration}

The author got the required ethical approvals including Ministry of Health, research ethics committee of AlAqsa Martyr's Hospital, head of cardiology department and informed consent of the participants.

\section{Results}

\subsection{Baseline Characteristics of Participants}

Table 2 shows the baseline characteristics of the participants, it was noticed that the mean of age among cases was $(68.28 \pm 8.01)$ higher than controls $(57.82 \pm 9.61)$ with significant statistical difference $(\mathrm{P}=0.01)$, the percent of males (54.0\%) was higher than females (46.0\%) among cases. However, no statistically significant difference was found between cases and controls. In addition, percent of cases who was living in a sunny houses (52.0\%) was lower than controls (82.0\%) with significant statistical difference $(\mathrm{P}=0.01)$. Moreover, percent of cases who was daily exposed to sun $(60.0 \%)$ was lower than controls $(80.0 \%)$ with statistical difference $(\mathrm{P}=$ $0.024)$, and the mean of daily exposure to sun per minutes among cases was (24.2 \pm 28.50$)$ lower than controls $(40.5 \pm 26.05)$ with significant statistical difference $(P=0.004)$.

\subsection{Clinical Cutoff Points for Vitamin D Status and CHD}

\subsubsection{Vitamin D Rich Food Intake}

Figure 1 shows the mean of servings intake of Vitamin D rich food, it is obvious that cases were consumed less servings of Vitamin D rich food including whole milk, yogurt, tuna, sardine, liver, and eggs when compared with controls, that differences were statically significant for all values $(\mathrm{P}<0.05)$.

\subsubsection{Serum Vitamin D}

Table 3 shows the levels of serum Vitamin D, divided into three levels optimal or sufficient, insufficiency, and deficiency. Percent of Vitamin D deficiency among cases (42.0\%) was higher than controls (16.0\%) with statistical difference $(\mathrm{P}=0.002)$. However, it was noticed that the mean of serum Vitamin $\mathrm{D}$ among cases was (79.36 $\pm 65.408)$ higher than controls (122.32 \pm 67.869$)$ with significant statistical difference $(P=0.002$, Table 4$)$.

\subsection{Association between Serum Vitamin D and CRP}

Table 5 revealed the mean of serum Vitamin D in association with positive CRP was (79.95 \pm 70.640$)$ lower than negative CRP (106.06 \pm 68.966$)$, but not reached to the level of statistical significance $(P=0.13)$.

\subsection{Clinical Cutoff Points for CRP}

The results shows that (30.0\%) of cases had positive serum CRP which was higher than controls (10.0\%) with statistically significant difference $(\mathrm{P}=0.01)$ as shown in Table 6 .

\section{Discussion}

In our retrospective study, advance of age was positively associated with increased risk for CAD, that the mean of cases age was higher than controls with significant difference. This accords with many studies [30]-[34], that revealed CAD became common with advancing in age, among men by 45 years, and among women by 55 years. In addition, we found that percent of males was higher than females among cases group, many studies showed increased risk for development of CAD in men when compared with women in premenopausal age [35]-[37].

Regarding to sun exposure and duration of daily sunlight exposure, we found a direct relationship between sun exposure and duration of exposure and risk for developing CAD, that percent of cases who was living in sunny houses was lower than controls with significant statistical difference. Also, the mean of daily exposure to sun per minutes among cases was lower than controls with significant statistical difference. This agrees with recent a cross-sectional split-sample analysis study conducted by Kent et al. [38] suggested that lower long-term 


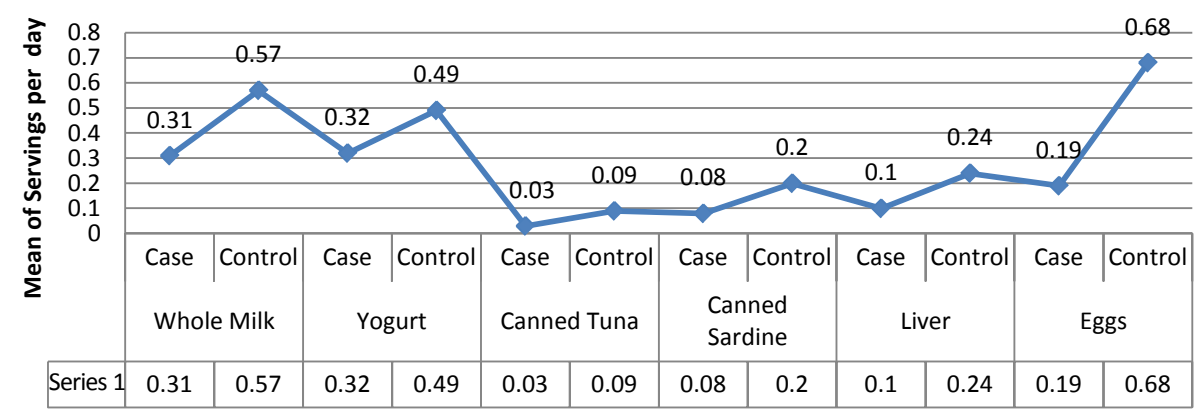

$\neg$ Number of daily Consumed Servings of Vitamin D Rich Food

Figure 1. Mean of servings of Vitamin D rich food consumed.

Table 2. Characteristics of participants.

\begin{tabular}{|c|c|c|c|c|c|}
\hline \multicolumn{2}{|c|}{ Variables } & Cases No. (\%) & Controls No. (\%) & $\begin{array}{c}\text { Total } \\
\mathrm{N}=100(\%)\end{array}$ & P-value \\
\hline \multicolumn{2}{|c|}{ Age (years) } & $68.28 \pm 8.01$ & $57.82 \pm 9.61$ & $63.05 \pm 10.25$ & $0.000^{*}$ \\
\hline \multirow{2}{*}{ Sex } & Male & 27 (54.0\%) & 19 (38.0\%) & $46(46.0 \%)$ & \multirow{2}{*}{0.079} \\
\hline & \multirow[t]{2}{*}{ Female } & $23(46.0 \%)$ & $31(62.0 \%)$ & $54(54.0 \%)$ & \\
\hline \multicolumn{5}{|c|}{ Living in sunny house } & \\
\hline \multicolumn{2}{|c|}{ Yes } & $26(52.0 \%)$ & $41(82.0 \%)$ & $67(67.0 \%)$ & \multirow{2}{*}{$0.001^{*}$} \\
\hline \multicolumn{2}{|c|}{ No } & $24(48.0 \%)$ & $9(18.0 \%)$ & $33(33.0 \%)$ & \\
\hline \multicolumn{6}{|c|}{ Sun exposure and mean duration of daily exposure } \\
\hline \multicolumn{2}{|c|}{ Yes } & $30(60.0 \%)$ & $40(80.0 \%)$ & $70(70.0 \%)$ & \multirow{2}{*}{$0.024^{*}$} \\
\hline \multicolumn{2}{|c|}{ No } & $20(40.0 \%)$ & $10(20.0 \%)$ & $30(30.0 \%)$ & \\
\hline \multicolumn{2}{|c|}{ Daily duration } & $24.2 \pm 28.50$ & $40.5 \pm 26.05$ & $32.3 \pm 28.37$ & $0.004^{*}$ \\
\hline
\end{tabular}

*Statistically significant $(\mathrm{P}<0.05)$.

Table 3. Levels of serum Vitamin D among participants.

\begin{tabular}{cccccc}
\hline \multirow{2}{*}{ Serum Vitamin D } & \multicolumn{2}{c}{ Subject } & Total & P-value \\
\cline { 2 - 3 } & Cases No. (\%) & Controls No. (\%) & N = 100 (\%) & $53(53.0 \%)$ & \\
\hline Optimal/sufficient & $18(36.0 \%)$ & $35(70.0 \%)$ & $18(18.0 \%)$ & $0.002^{*}$ \\
Insufficiency & $11(22.0 \%)$ & $7(14.0 \%)$ & $29(29.0 \%)$ & \\
Deficiency & $21(42.0 \%)$ & $8(16.0 \%)$ & & \\
\hline
\end{tabular}

*Statistically significant $(\mathrm{P}<0.05)$.

Table 4. Mean levels of serum Vitamin D among participants.

\begin{tabular}{ccccccc}
\hline Variables & Subject & N & Mean & Std. deviation & Std. error mean & P-value \\
\hline \multirow{2}{*}{ Serum Vitamin D } & Case & 50 & 79.36 & 65.408 & 9.250 & $0.002^{*}$ \\
& Control & 50 & 122.32 & 67.869 & 9.598 &
\end{tabular}

*Statistically significant $(\mathrm{P}<0.05)$.

Table 5. Comparing the means of Vitamin D and CRP.

\begin{tabular}{ccccccc}
\hline Variables & Serum CRP & N & Mean & Std. deviation & Std. error mean & P-value \\
\hline \multirow{2}{*}{ Serum Vitamin D } & Positive & 20 & 79.95 & 70.640 & 15.796 \\
& Negative & 80 & 106.06 & 68.966 & 7.711 \\
\hline
\end{tabular}


Table 6. Serum CRP among participants.

\begin{tabular}{ccccc}
\hline Serum CRP & Cases No. (\%) & Controls No. (\%) & Total & P-value \\
\hline Positive & $15(30.0 \%)$ & $5(10.0 \%)$ & $20(20.0 \%)$ & $\mathbf{0 . 0 1}^{*}$ \\
Negative & $35(70.0 \%)$ & $45(90.0 \%)$ & $80(80.0 \%)$ & \\
\hline
\end{tabular}

*Statistically significant $(\mathrm{P}<0.05)$.

sunlight exposure has an association with lower high-density lipoprotein levels. However, it known that highdensity lipoprotein levels is associated with CAD [39]-[42].

Our analyses revealed that an inverse relationship in relation to the number of serving of Vitamin D such as whole milk, yogurt, tuna, sardine, liver, and eggs and the risk for CAD. Regarding to serum Vitamin D, our study showed a direct relationship between Vitamin D deficiency and the risk for CAD among cases with statistical significance. This agrees with Giovannucci et al. [13] assessed the association between serum Vitamin D and risk of coronary disease among men who participated in the health professionals follow-up study. Men with Vitamin D deficiency ( $\leq 15 \mathrm{ng} / \mathrm{ml}$ or $37 \mathrm{nmol} / \mathrm{L}$ ) were at significantly increased risk of developing myocardial infarction, compared with those with sufficient levels of Vitamin D ( $\geq 30 \mathrm{ng} / \mathrm{mL}$ or $75 \mathrm{nmol} / \mathrm{L}$ ) (RR 2.09; 95\% CI: 1.24 - 3.54). Another study showed high risk of CAD mortality with low Vitamin D levels [43]. A community-based case-control study conducted in New Zealand found by Lavie et al. [44] found men with myocardial infraction had lower Vitamin D levels compared to controls. On other Hand, Pilz et al. [45] concluded low serum Vitamin D can only be considered a CVD risk marker, as Vitamin D supplementation with doses recommended for osteoporosis treatment is neither proven to be beneficial nor harmful in cardiovascular diseases. They made their conclusion depending on randomized controlled trials (RCTs) on Vitamin D which had largely failed to show its beneficial effects on cardiovascular diseases and its conventional risk factors as they reported. In addition, they considered most of prior Vitamin D RCTs not designed to assess cardiovascular outcomes, some large RCTs have been initiated to evaluate the efficacy of Vitamin D supplementation on cardiovascular events in the general population. When considering the history of previous disappointing Vitamin RCTs in general populations, more emphasis should be placed on RCTs among severely Vitamin D-deficient populations who would most likely benefit from Vitamin D treatment.

Our study showed a direct relationship between positive serum CRP and the risk for CAD among cases with statistical significance. This agrees with El-Hissi et al. [30] who conducted a case control study included 100 subjects and assessed association between serum CRP and risk of CAD, they found a direct statistically significant relationship, in which percent of cases with positive CRP was (32.9\%) higher than controls (12.9\%).

Moreover, we found association between serum Vitamin D deficiency and positive CRP, but not reached to the level of statistical significance. This agrees with study conducted by Amer and Qayyum in Johns Hopkins University School of Medicine in Maryland [46], who observed a positive relation between Vitamin D above its median and CRP [geometric mean CRP change $0.06 \mathrm{mg} / \mathrm{dl}$ for each $10 \mathrm{ng} / \mathrm{ml}$ change in Vitamin D, 95\% CI 0.02 to 0.11) after adjusting for traditional cardiovascular risk factors. Controversial studies on the relationship between Vitamin D and serum CRP levels. Ashraf et al. [47] measured serum high-sensitivity C-reactive protein (hs-CRP) and Vitamin D in 62 healthy adults, they concluded an inverse association between hs-CRP and Vitamin $\mathrm{D}$ in subjects with $<20 \mathrm{ng} / \mathrm{mL}$ Vitamin $\mathrm{D}(\mathrm{n}=27)$. In addition, Michos et al. [48] study failed to detect a cross-sectional association between serum Vitamin D levels and CRP in 650 Amish participants.

\section{Conclusion}

This study showed that Vitamin D deficiency was associated with positive C-reactive protein in patients with coronary artery disease. Further studies are needed to determine the effect of Vitamin D supplementation on morbidity and mortality of coronary artery disease on a larger scale of population.

\section{Acknowledgements}

The author acknowledges the members of staff of the Cardiology department and medical laboratory of Al-Aqsa Martyr's Hospital for their fruitful contributions. Great thanks extended to the participants and their families of our study. 


\section{References}

[1] (2010) Global Status Report on Noncommunicable Diseases. World Health Organization, Geneva.

[2] Murphy, S.L., Xu, J.Q. and Kochanek, K.D. (2013) Deaths: Final Data for 2010. National Vital Statistics Reports, 61. http://www.cdc.gov/nchs/data/nvsr/nvsr61/nvsr61_04.pdf

[3] Ministry of Health (2012) Health Annual Report Palestine 2011. Ministry of Health, Palestinian Health Information Center, Nablus.

[4] Nabel, E.G. and Braunwald, E. (2012) A Tale of Coronary Artery Disease and Myocardial Infarction. New England Journal of Medicine, 366, 54. http://dx.doi.org/10.1056/NEJMra1112570

[5] Hansson, G.K. (2005) Inflammation, Atherosclerosis, and Coronary Artery Disease. New England Journal of Medicine, 352, 1685-1695. http://dx.doi.org/10.1056/NEJMra043430

[6] Hansson, G.K. (2001) Immune Mechanisms in Atherosclerosis. Arteriosclerosis, Thrombosis, and Vascular Biology, 21, 1876-1890. http://dx.doi.org/10.1161/hq1201.100220

[7] Binder, C.J., Hartvigsen, K., Chang, M.K., et al. (2004) IL-5 Links Adaptive and Natural Immunity Specific for Epitopes of Oxidized LDL and Protects from Atherosclerosis. Journal of Clinical Investigation, 114, 427-437. http://dx.doi.org/10.1172/JCI200420479

[8] Mallat, Z., Besnard, S., Duriez, M., et al. (1999) Protective Role of Interleukin-10 in Atherosclerosis. Circulation Research, 85, e17-e24. http://dx.doi.org/10.1161/01.RES.85.8.e17

[9] Caligiuri, G., Rudling, M., Ollivier, V., et al. (2003) Interleukin-10 Deficiency Increases Atherosclerosis, Thrombosis, and Low-Density Lipoproteins in Apolipoprotein E Knockout Mice. Molecular Medicine, 9, 10-17.

[10] Chilton, R.J. (2004) Pathophysiology of Coronary Heart Disease: A Brief Review. Journal of the American Osteopathic Association, 104, S5-S8.

[11] Liuzzo, G., Biasucci, L.M., Rebuzzi, A.G., Gallimore, J.R., Caligiuri, G., Lanza, G.A., et al. (1996) Plasma Protein Acute-Phase Response in Unstable Angina Is Not Induced by Ischemic Injury. Circulation, 94, 2373-2380. http://dx.doi.org/10.1161/01.CIR.94.10.2373

[12] Brewer, L.C., Michos, E.D. and Reis, J.P. (2011) Vitamin D in Atherosclerosis, Vascular Disease, and Endothelial Function. Current Drug Targets, 12, 54-60. http://dx.doi.org/10.2174/138945011793591617

[13] Giovannucci, E., Liu, Y., Hollis, B.W. and Rimm, E.B. (2008) 25-Hydroxyvitamin D and Risk of Myocardial Infarction in Men. Archives of Internal Medicine, 168, 1174-1180. http://dx.doi.org/10.1001/archinte.168.11.1174

[14] Wang, T.J., Pencina, M.J., Booth, S.L., Jacques, P.F., Ingelsson, E., Lanier, K., Benjamin, E.J., D’Agostino, R.B., Wolf, M. and Vasan, R.S. (2008) Vitamin D Deficiency and Risk of Cardiovascular Disease. Circulation, 117, 503-511. http://dx.doi.org/10.1161/CIRCULATIONAHA.107.706127

[15] Dobnig, H., Pilz, S., Scharnagl, H., Renner, W., Seelhorst, U., Wellnitz, B., et al. (2008) Independent Association of Low Serum 25-Hydroxyvitamin D and 1, 25-Dihydroxyvitamin D Levels with All-Cause and Cardiovascular Mortality. Archives of Internal Medicine, 168, 1340-1349. http://dx.doi.org/10.1001/archinte.168.12.1340

[16] Holick, M.F. (2007) Vitamin D Deficiency. The New England Journal of Medicine, 357, 266-281. http://dx.doi.org/10.1056/NEJMra070553

[17] Institute of Medicine (IOM), Food and Nutrition Board (2010) Dietary Reference Intakes for Calcium and Vitamin D. National Academy Press, Washington DC.

[18] Holick, M.F. (2004) Vitamin D. Importance in the Prevention of Cancers, Type 1 Diabetes, Heart Disease, and Osteoporosis. The American Journal of Clinical Nutrition, 79, 362-371.

[19] Rosen, C.J., Adams, J.S., Bikle, D.D., Black, D.M., Demay, M.B., Manson, J.E., et al. (2012) The Nonskeletal Effects of Vitamin D: An Endocrine Society Scientific Statement. Endocrine Reviews, 33, 456-492. http://dx.doi.org/10.1210/er.2012-1000

[20] Elamin, M.B., Abu Elnour, N.O., Elamin, K.B., Fatourechi, M.M., Alkatib, A.A., Almandoz, J.P., et al. (2011) Vitamin D and Cardiovascular Outcomes: A Systematic Review and Meta-Analysis. Journal of Clinical Endocrinology \& Metabolism, 96, 1931-1942. http://dx.doi.org/10.1210/jc.2011-0398

[21] Truesdell, D., Shin, H., Liu, P.Y. and Ilich, J.Z. (2011) Vitamin D Status and Framingham Risk Score in Overweight Postmenopausal Women. Journal of Women's Health, 20, 1341-1348. http://dx.doi.org/10.1089/jwh.2010.2599

[22] Wexler, L., Brundage, B., Crouse, J., Detrano, R., Fuster, V., Maddahi, J., Rumberger, J., Stanford, W., White, R. and Taubert, K. (1996) Coronary Artery Calcification: Pathophysiology, Epidemiology, Imaging Methods, and Clinical Implications: A Statement for Health Professionals from the American Heart Association. Circulation, 94, 1175-1192. http://dx.doi.org/10.1161/01.CIR.94.5.1175

[23] Spiro, A. and Buttriss, J.L. (2014) Vitamin D: An Overview of Vitamin D Status and Intake in Europe. Nutrition Bulle- 
tin, 39, 322-350. http://dx.doi.org/10.1111/nbu.12108

[24] Norman, A.W. (2008) From Vitamin D to Hormone D: Fundamentals of the Vitamin D Endocrine System Essential for Good Health. The American Journal of Clinical Nutrition, 88, 491S-499S.

[25] Holick, M.F. and Chen, T.C. (2008) Vitamin D Deficiency: A Worldwide Problem with Health Consequences. The American Journal of Clinical Nutrition, 87, 1080S-1086S.

[26] Kao, P.C., Shiesh, S.C. and Wu, T.J. (2006) Serum C-Reactive Protein as a Marker for Wellness Assessment. Annals of Clinical and Laboratory Science, 36, 163-169.

[27] USDA, Agricultural Research Service (2013) Nutrient Intakes Percent of Population 2 Years Old and over with Adequate Intakes Based on Average Requirement. Community Nutrition Mapping Project. http://www.ars.usda.gov/services/docs.htm?docid=22808

[28] Calbiotech (2013) 25-OH Vitamin D ELISA. http://www.calbiotech.com/component/dropfiles/?task=frontfile.download\&id=577

[29] Anonymous (2014) CRP-Latex Agglutination Test-Inmesco GmbH, Germany. http://www.inmesco.de/pdf/customer-support/rapid-latex-slide-test/inmesco-crp-latex-agglutination-test.pdf

[30] El-Hissi, J., Ahmed, A., Al-Masri, I., El-Sakka, M., Masad, A. and Najem, A. (2014) Dietary Magnesium Intake Related to C-Reactive Protein in Newly Diagnosed Coronary Heart Disease Patients at Middle Zone, Gaza Strip. A Hospital Based Study. Pharmacology \& Pharmacy, 5, 601-611. http://dx.doi.org/10.4236/pp.2014.57070

[31] Urden, L.D., Stacy, K.M. and Lough, M.E. (2002) Critical Care Nursing-Diagnosis and Management. 4th Edition, Mosby, St. Louis, 395-398.

[32] Idris, I., Deepa, R., Fernando, D.J. and Mohan, V. (2008) Relation between Age and Coronary Heart Disease Risk in Asian Indian Patients with Diabetes: A Cross-Sectional and Prospective Cohort Study. Diabetes Research and Clinical Practice, 81, 243-249.

[33] National Heart, Lung, and Blood Institute, NHLBI (2011) Coronary Heart Disease Risk factors. National Institutes of Health: National Heart Lung and Blood Institute. http://www.nhlbi.nih.gov

[34] Amani, R. and Sharifi, N. (2012) Cardiovascular Disease Risk Factors. In: Gaze, D., Ed., The Cardiovascular System Physiology, Diagnostics and Clinical Implications, InTech, Winchester, 280-310.

[35] Jousilahti, P., Vartiainen, E., Tuomilehto, J. and Puska, P. (1999) Sex, Age, Cardiovascular Risk Factors, and Coronary Heart Disease. A Prospective Follow-Up Study of 14786 Middle-Aged Men and Women in Finland. Circulation, 99, 1165-1172. http://dx.doi.org/10.1161/01.CIR.99.9.1165

[36] American Heart Association, AHA (2013) Coronary Artery Disease-Coronary Heart Disease. American Heart Association, Dallas.

http://www.heart.org/HEARTORG/Conditions/More/MyHeartandStrokeNews/Coronary-Artery-Disease---The-ABCsof-CAD UCM 436416 Article.jsp

[37] World Heart Federation, WHF (2013) Cardiovascular Disease Risk Factors. World Heart Federation, Geneva. http://www.world-heart-federation.org/press/fact-sheets/cardiovascular-disease-risk-factors/

[38] Kent, S.T., Cushman, M., Howard, G., Judd, S.E., Crosson, W.L., Al-Hamdan, M.Z. and McClure, L.A. (2014) Sunlight Exposure and Cardiovascular Risk Factors in the REGARDS Study: A Cross-Sectional Split-Sample Analysis. BMC Neurology, 14, 133. http://dx.doi.org/10.1186/1471-2377-14-133

[39] Di Angelantonio, E., Sarwar, N., Perry, P., Kaptoge, S., Ray, K.K., Thompson, A., et al. (2009) Emerging Risk Factors Collaboration Major Lipids, Apolipoproteins, and Risk of Vascular Disease. Journal of the American Medical Association, 302, 1993-2000. http://dx.doi.org/10.1001/jama.2009.1619

[40] Assmann, G., Schulte, H., von Eckardstein, A. and Huang, Y. (1996) High-Density Lipoprotein Cholesterol as a Predictor of Coronary Heart Disease Risk. The PROCAM Experience and Pathophysiological Implications for Reverse Cholesterol Transport. Atherosclerosis, 124, S11-S20. http://dx.doi.org/10.1016/0021-9150(96)05852-2

[41] Sachdeva, A., Cannon, C.P., Deedwania, P.C., Labresh, K.A., Smith Jr., S.C., Dai, D., et al. (2009) Lipid Levels in Patients Hospitalized with Coronary Artery Disease: An Analysis of 136,905 Hospitalizations in Get with the Guidelines. American Heart Journal, 157, 111-117. http://dx.doi.org/10.1016/j.ahj.2008.08.010

[42] Heart Protection Study Collaborative Group MRC/BHF Heart Protection (2002) Study of Cholesterol Lowering with Simvastatin in 20,536 High-Risk Individuals: A Randomized Placebo-Controlled Trial. The Lancet, 360, 7-22. http://dx.doi.org/10.1016/S0140-6736(02)09327-3

[43] Zittermann, A., Iodice, S., Pilz, S., Grant, W.B., Bagnardi, V. and Gandini, S. (2012) Vitamin D Deficiency and Mortality Risk in the General Population: A Meta-Analysis of Prospective Cohort Studies. The American Journal of Clinical Nutrition, 95, 91-100. http://dx.doi.org/10.3945/ajcn.111.014779

[44] Lavie, C.J., Lee, J.H. and Milani, R.V. (2011) Vitamin D and Cardiovascular Disease: Will It Live Up to Its Hype? 
Journal of the American College of Cardiology, 58, 1547-1556. http://dx.doi.org/10.1016/j.jacc.2011.07.008

[45] Pilz, S., März, W., Wellnitz, B., Seelhorst, U., Fahrleitner-Pammer, A., Dimai, H.P., Boehm, B.O. and Dobnig, H. (2008) Association of Vitamin D Deficiency with Heart Failure and Sudden Cardiac Death in a Large Cross-Sectional Study of Patients Referred for Coronary Angiography. The Journal of Clinical Endocrinology \& Metabolism, 93, 3927-3935. http://dx.doi.org/10.1210/jc.2008-0784

[46] Amer, M. and Qayyum, R. (2012) Relation between Serum 25-Hydroxyvitamin D and C-Reactive Protein in Asymptomatic Adults (From the Continuous National Health and Nutrition Examination Survey 2001 to 2006). The American Journal of Cardiology, 109, 226-230. http://dx.doi.org/10.1016/j.amjcard.2011.08.032

[47] Ashraf, A.P., Fisher, G., Alvarez, J., Dudenbostel, T., Calhoun, D.A., Szalai, A.J. and Gower, B.A. (2012) Associations of C-Reactive Protein to Indices of Vascular Health and the Influence of Serum 25(OH)D Status in Healthy Adults. Journal of Nutrition and Metabolism, 2012, 1-6. http://dx.doi.org/10.1155/2012/475975

[48] Michos, E.D., Streeten, E.A., Ryan, K.A., Rampersaud, E., Peyser, P.A., Bielak, L.F., et al. (2009) Serum 25-Hydroxyvitamin D Levels Are Not Associated with Subclinical Vascular Disease or C-Reactive Protein in the Old Order Amish. Calcified Tissue International, 84, 195-202. http://dx.doi.org/10.1007/s00223-008-9209-3

\section{List of Abbreviations}

CVD: Cardiovascular Disease;

CAD: Coronary Artery Disease;

CRP: C-Reactive Protein;

FFQ: Food Frequency Questionnaire;

hs-CRP: High-Sensitivity C-Reactive Protein;

IOM: Institute of Medicine;

IU: International Units;

LDL: Low Density Lipoprotein;

RCTs: Randomized Controlled Trials;

RDA: Recommended Dietary Allowance;

SPSS: Statistical Package for the Social Sciences;

UVB: Ultraviolet B;

USDA: United States Agriculture Department. 
Scientific Research Publishing (SCIRP) is one of the largest Open Access journal publishers. It is currently publishing more than 200 open access, online, peer-reviewed journals covering a wide range of academic disciplines. SCIRP serves the worldwide academic communities and contributes to the progress and application of science with its publication.

Other selected journals from SCIRP are listed as below. Submit your manuscript to us via either submit@scirp.org or Online Submission Portal.
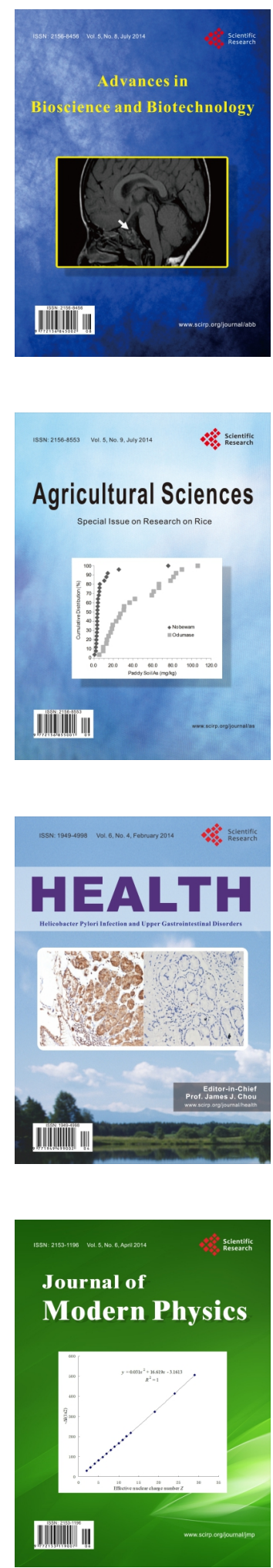
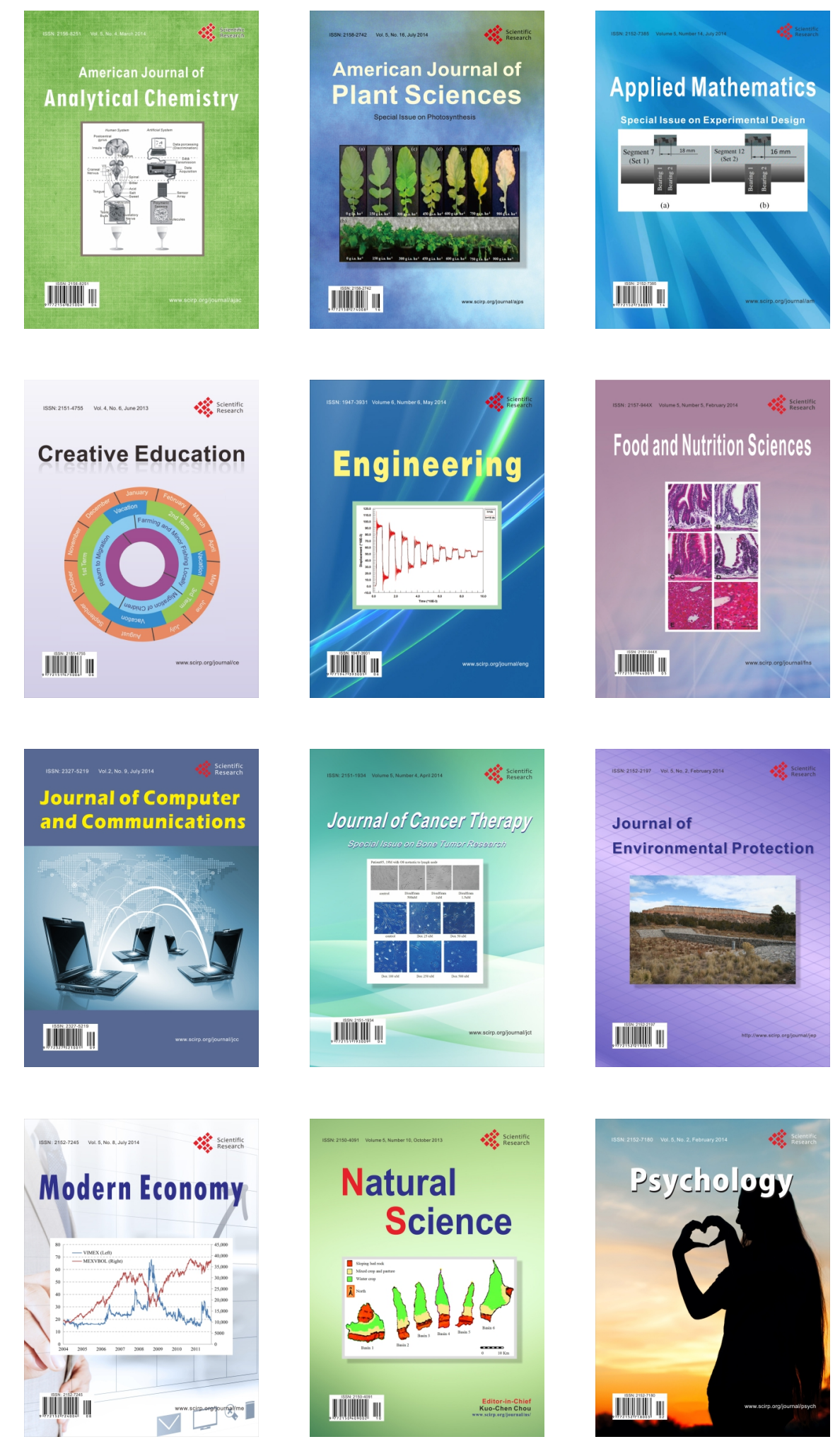